\title{
Prevalence and predictors of Cervical Intraepithelial Neoplasia among HIV infected women at Bugando Medical Centre, Mwanza-Tanzania
}

\author{
Lilian Kafuruki ${ }^{1}$, Peter Fabian Rambau ${ }^{2 *}$, Anthony Massinde ${ }^{1+}$ and Nestory Masalü ${ }^{3+}$
}

\begin{abstract}
Introduction: Cancer of the cervix rank the second most common cause of cancer related deaths among women in Sub-Saharan Africa. It is estimated that 529, 409 new cases are diagnosed annually with a mortality rate approaching 274,883 per year. Cervical Intraepithelial Neoplasia (CIN) precedes almost all cervical cancers. The incidence rate of CIN among HIV infected women is five times higher as compared to the rate in HIV negative women. The screening for cervical dysplasia and an appropriate management in women with CIN are effective methods for preventing cervical cancer. This study was done to determine the prevalence and predictors of CIN among a HIV infected women attending Care and Treatment centre (CTC) at Bugando Medical Centre (BMC).
\end{abstract}

Methods: A cross sectional survey was undertaken among HIV infected women aged 18 years and above attending at BMC CTC clinic between February and March 2013. Visual Inspection with Acetic acid (VIA) was used as the screening method for detection of CIN. Socio-demographic, reproductive and clinical information was obtained from participants and the blood was collected for $\mathrm{CD}_{4}$ lymphocyte count. Cervical punch biopsy for histological examination was performed for those who had VIA positive test. Data were entered and analyzed using STATA Version 12.0 soft ware.

Results: A total number of 95 (26.8\%) participants had positive VIA test among three hundred and fifty-five (355) HIV infected women. Histology results showed; 4(4.2\%) were normal, 26 (27.4\%) had an inflammatory lesion, 58 (61.1\%) had CIN and 7(7.3\%) had invasive cervical cancer. CIN was found to be associated with a history of multiple sexual partners $(P<0.001)$, a history of genital warts $(P<0.001)$, and a history of STI $(P=0.010)$.

Conclusion: The Cervical Intraepithelial Neoplasia is a problem among HIV infected women. A history of multiple sexual partners, a history of genital warts, a history STI and a low baseline CD4 T lymphocyte were significant predictors for CIN. Screening for Cervical Intraepithelial Neoplasia is recommended for all women with HIV.

Keywords: Cervical intraepithelial Neoplasia, HIV, Mwanza

\footnotetext{
* Correspondence: prambau@bugando.ac.tz

${ }^{\dagger}$ Equal contributors

2Department of Pathology, Catholic University of Health Sciences and Allied

Sciences (CUHAS-Bugando), Box 1464, Mwanza, Tanzania

Full list of author information is available at the end of the article
} 


\section{Background}

Cervical cancer and HIV/AIDS are major public health problems. Worldwide, cancer of the cervix is the second most common cancer among women, with 529,409 new cases and 274,883 deaths annually. The developing countries constitute $86 \%$ of the newly diagnosed cases and $88 \%$ of the deaths [1]. The age-adjusted incidence rate of cervical cancer in Tanzania is estimated to be 50.9 cases per 100,000 world standard women population, with an age adjusted mortality rate of 37.5 per 100,000 [2]. Cervical Intraepithelial Neoplasia (CIN) precedes almost all cervical cancers. A study undertaken in Conakry Guinea, reported that the incidence rate of CIN among HIV-infected women was 4-5 times higher compared to those with no HIV infection [3]. In an attempt to reduce the cervical cancer burden, the Ocean Road Cancer Institute in Dar-Es-Salaam introduced a cervical cancer screening programme using Visual Inspection with acetic acid (VIA) in different satellite clinics throughout the country [4]. Despite this, there has been a rise in the incidence of cervical cancer in Tanzania [5].

In developing countries, the prevalence of CIN among HIV infected women is reported to be very high [6]. A study in Lusaka Zambia evaluated 150 women, using the Papanicolau smear test; more than $93 \%$ had CIN with a median CD4 count of 165 cells $/ \mathrm{mm}^{3}$ [6].

The high prevalence of cervical cancer in patients with advanced HIV/AIDS infection led to its inclusion among AIDS defining conditions [5]. Currently, it is recognized that HIV infected women have a higher prevalence of Human Papilloma Virus (HPV) and the risk of infection increases with the extent of immunosuppression [7]. A higher prevalence of persistent infections with multiple high risk-HPV strains contributes to a greater risk of precancerous lesions [7]. The natural history of cervical cancer follows a prolonged period of a pre-malignant disease stage, commonly described as CIN which can take as up to 10 years before the progression to invasive cancer [8]. This shows that there is sufficient time for the women to be screened for cervical cancer and receive the appropriate treatment [7]. Studies have reported that, among HIV infected women, the risk of developing cervical cancer is 10 years earlier than in the general population, with a high rate of progression to an advanced disease with a poor prognosis [9]. Other risk factors include: age, lifetime number of sexual partners (more than four), early sexual debut, high parity, immunosuppression, smoking and oral contraceptive use for more than five years $[9,10]$.

The Papanicolau smear test is the most widely used cervical cancer screening test, having a higher sensitivity and specificity compared to other tests [11]. However, currently, Visual Inspection with Acetic acid has been advocated as an alternative screening method to the
Papanicolau smear in developing countries and this test has high sensitivity and specificity [12]. The Papanicolau smear is difficult to implement in resource limited settings due to inadequate laboratories, and lack of expert specialists. It requests a greater number of visits than the VIA and therefore increase the cost. VIA provides an effective alternative method with fewer logistical and technical constraints [12]. A study conducted in 1999 in Zimbabwe showed that VIA was a valuable tool for the detection of pre-cancerous lesions with a sensitivity of $76.7 \%$ compared to $44.3 \%$ for cytology. However, the specificity of VIA was lower (64.1\%) than that of cytology $(90.6 \%)$. The authors also found that the cervical abnormalities detected by VIA, 75\% concurred with those detected by biopsy [13].

Although numerous studies have documented the association between HIV infection and the presence of CIN, very few have assessed the associated risk factors specific to HIV infected women. The prevalence of CIN in Tanzania is quite variable, ranging from $2.9 \%$ to $38 \%$ $[14,15]$. A study conducted among attendees at the Makongoro Clinic in Mwanza Region found the prevalence of Squamous Intraepithelial Lesion (SIL) to be 7\%; HPV was $34 \%$, whereby $83 \%$ of HPV was of high risk oncogenic strains [16]. The high prevalence of HPV and CIN among a low risk population is a matter of great concern, which emphasizes the need to conduct a study on the prevalence and predictors of CIN among a high risk population.

Previous studies have recommended the need for cervical cancer screening among HIV infected women. However none have suggested which screening test should be used, Papanicolau smear or VIA, for the detection of premalignant cervical lesions, especially in a low resource setting $[6,14,17]$. This is partly due to the lack of documentation concerning screening tests and protocols for HIV infected women. The aim of the present study was to determine the number of women with biopsy proven CIN and the predictors of CIN in HIV infected women using VIA as an alternative screening method to the Papanicolau smear in a resource limited setting.

\section{Methods}

A cross sectional study was conducted between February and March 2013 at the HIV Care and Treatment Centre at Bugando Medical Centre, which receives an average of 80 visiting HIV infected women per day [18]. The clinic attends to patients who are on anti-retroviral drugs and to those who have not started antiretroviral therapy. The exclusion criteria for participation in the study were: allergy to acetic acid, prior total hysterectomy, wedge resection of the cervix, previous abnormal Papanicolau smear, a history of cervical cancer and pregnancy. 
Convenience sampling was used to select the first participant each day from CTC register book. Thereafter every third person was included systematically in the study, until the required sample was reached. In case of refusal or not meeting the inclusion criteria, the next person was selected.

Data was collected using a structured pre-tested questionnaire. The interview was conducted in the language in which the interviewee was proficient (Swahili, English, indigenous language) with the help of an interpreter when necessary. The gathered information included socio-demographic characteristics, gynecological history, obstetric history and whether she had previously been screened for cervical cancer.

Participants with a proven HIV positive diagnosis had a CD4 lymphocyte count check using a blood sample collected through venopuncture.

A pelvic/Speculum examination was performed for the recruited participants in which inspection and visualization under an adequate light source was conducted. A solution of freshly diluted $5 \%$ acetic acid was then painted to the mucosa of the cervix using a cotton swab tipped applicator. The detection of any distinct Acetowhite areas within the transformation zone was considered to be positive after 4 minutes of waiting. Punch biopsies to determine the accuracy of the cervical evaluation were performed for all participants who were VIA positive. The samples were fixed in $10 \%$ formalin, labeled with the patients study number and sent to the laboratory for histo-pathological examination. Those with abnormal histological results were referred for follow up and management at the gynecology/ oncology clinic. Cryotherapy was performed on the same setting for lesions about $5 \mathrm{~cm}$ width or above. For clinical suspicious cervical cancerous lesions, patients were referred to a gynaecologist for appropriate care and management.

Data were double-entered in Epidata 3.1 (Epidata Association Odense Denmark) and cleaned and analyzed using STATA 12.0 (College Station, Texas, USA). Descriptive statistics were used to demonstrate the demographic data and prevalence of cervical lesions among HIV infected women using VIA. Univariate and multivariate logistic regression were carried out to analyze factors/predictors of cervical intraepithelial neoplasia. Estimation of odds ratios and their 95\% confidence interval, comparing the odds of each outcome between predictor groups was also done. An association was considered significant when the p-value was less than 0.05 .

\section{Results}

A total number of 1853 HIV infected women attended at the HIV clinic of BMC between February and March 2013. Three hundred and fifty five (355) HIV infected women were eligible for the study and were screened for the cancer of cervix. The median age of the participants was 38 years (range 18-63 years). The majority of participants were from urban area $(81 \%)$ and a third was married women (33\%). The majority of the respondents 225 (71.8\%) had primary education.

Among the women with malignant and pre-malignant cervical lesions, $44(75 \%)$ had a sexual debut before the age of 18 years and a median number of sexual partners reported in this study was four (range 1-8). A history of genital warts and a history of STI were reported among 53(91.4\%) and 56 (97\%) of the women with CIN respectively. None of the participants had ever been screened for cervical cancer previously. [See Tables 1 and 2].

Ninety-five (95) HIV infected women tested positive after the VIA test. This group was further subjected to a histo-pathological examination and results were as follows: 4 (4.2\%) were normal, 26 (27.4\%) had an inflammatory lesion, 58(61.1\%) had CIN, whereby 31 (53.4\%) had CIN1 and 27(46.6\%) had CIN2/3. Seven women (7.37\%) had invasive cervical cancer.

An age at first sexual intercourse of less than 18 years was associated with CIN (OR 0.14; 95\%CI 0.07-0.27, $\mathrm{P}<0.001)$. A number of life time sexual partners of more than 1 increased the likelihood of having CIN (OR 1; 95\% CI 0.06-0.21, $\mathrm{P}<0.001)$ and a history of genital warts was significantly associated with CIN (OR 27.33; 95\%CI 10.6-70.8 $\mathrm{P}<0.001)$. CIN was more common in participants with a previous history of STI (OR 13; 95\%CI 3.154.3, $\mathrm{P}<0.001)$. [See Table 3 and 4]

Exposure to cigarette smoking was more likely to increase the risk of CIN than non-exposure (OR 1.95, 95\% CI 1.01-3.78, $\mathrm{P}=0.04)$. The prevalence of $\mathrm{CIN}$ was higher among women with a baseline CD4 $\mathrm{T}$ lymphocytes count of less than 200 cells $/ \mathrm{mm}^{3}$ (OR 1; 95\% CI 0 , 25-0.80, $\mathrm{P}=0.007$ ).

There was no significant association between CIN and age, marital status, contraceptive use, parity or current CD4 count. The use of HAART and the number of years since HIV diagnosis were not associated with CIN [See Table 4].

The predictors which had a significant association with CIN in Univariate analysis were subjected to multivariate analysis. The predictors for CIN among HIV infected women were the number of life time sexual partners (Adjusted OR 4.06; 95\% CI 1.86-8.88, $\mathrm{P}<0.001$ ), a history of genital warts (Adjusted OR 16.6; 95\% CI5.91- 47.0, $\mathrm{P}<0.001$ ), a history of STI (Adjusted OR 7.39; 95\% CI 1.67-33.66, $\mathrm{P}=0.010$ ) and a baseline $\mathrm{CD} 4$ lymphocytes count of less than 200cells $/ \mathrm{mm}^{3}$ (Adjusted OR 2.71; 95\% CI 01.24-5.90, $\mathrm{P}=0.012$ ) [ See Table 5].

\section{Discussion}

In this study 95 out of 355 (26.8\%) HIV infected women had cervical lesions (VIA positive) that warranted histological evaluation. This finding was lower than that 
Table 1 Socio demographic, clinical and reproductive characteristics of HIV+ women screened for CIN

\begin{tabular}{|c|c|c|c|c|c|c|}
\hline \multirow[t]{2}{*}{ Variables } & \multicolumn{2}{|c|}{$\begin{array}{l}\text { CIN Negative } \\
(n=297)\end{array}$} & \multicolumn{2}{|c|}{$\begin{array}{l}\text { CIN Positive } \\
(n=58)(n=58)\end{array}$} & \multicolumn{2}{|c|}{$\begin{array}{c}\text { Total } \\
(n=355)\end{array}$} \\
\hline & $\mathbf{n}$ & $\%$ & $n$ & $\%$ & $\mathrm{n}$ & $\%$ \\
\hline \multicolumn{7}{|l|}{ Age } \\
\hline $18-25$ years & 20 & (6.7) & 1 & $(1.7)$ & 21 & (5.9) \\
\hline $26-35$ years & 95 & $(32.0)$ & 26 & $(44.8)$ & 121 & (34.1) \\
\hline $36-49$ years & 148 & $(49.8)$ & 24 & (41.4) & 172 & $(48.4)$ \\
\hline $50+$ years & 34 & $(11.5)$ & 7 & $(12.1)$ & 41 & (11.6) \\
\hline \multicolumn{7}{|l|}{ Residence } \\
\hline Urban & 244 & $(82.2)$ & 44 & (75.9) & 288 & $(81.1)$ \\
\hline Rural & 53 & $(17.8)$ & 14 & $(24.1)$ & 67 & (18.9) \\
\hline \multicolumn{7}{|l|}{ Marital status } \\
\hline Single & 32 & $(10.8)$ & 5 & $(8.60)$ & 37 & $(10.4)$ \\
\hline Married & 107 & $(36.0)$ & 12 & $(20.7)$ & 119 & (33.5) \\
\hline Divorced & 74 & $(24.9)$ & 20 & $(34.5)$ & 94 & $(26.5)$ \\
\hline Separated & 4 & (1.4) & 2 & $(3.50)$ & 6 & $(1.7)$ \\
\hline Widowed & 80 & $(26.9)$ & 19 & $(32.8)$ & 99 & $(27.9)$ \\
\hline \multicolumn{7}{|l|}{ Education } \\
\hline None & 50 & $(16.8)$ & 5 & (8.6) & 55 & (15.5) \\
\hline Primary & 208 & $(70.0)$ & 47 & $(81.0)$ & 255 & (71.8) \\
\hline Secondary & 32 & (10.8) & 4 & (6.9) & 36 & $(10.1)$ \\
\hline College or above & 7 & (2.4) & 2 & (3.5) & 9 & (2.5) \\
\hline \multicolumn{7}{|l|}{ Sexual Debut } \\
\hline Less than 18 yrs & 90 & $(30.3)$ & 44 & $(75.9)$ & 134 & $(37.8)$ \\
\hline 18 years and above & 207 & $(69.7)$ & 14 & $(24.1)$ & 221 & $(62.2)$ \\
\hline \multicolumn{7}{|c|}{ Lifetime sexual partners } \\
\hline One partner & 16 & $(5.4)$ & 0 & $(0.0)$ & 5 & (4.5) \\
\hline 2-5 partners & 235 & $(79.1)$ & 21 & $(36.2)$ & 256 & $(72.1)$ \\
\hline $5+$ partners & 46 & $(15.5)$ & 37 & $(63.8)$ & 83 & $(23.4)$ \\
\hline \multicolumn{7}{|l|}{ Condom use } \\
\hline Never & 134 & $(45.1)$ & 33 & $(56.9)$ & 167 & $(47.0)$ \\
\hline Sometimes & 133 & $(44.8)$ & 21 & $(36.20)$ & 154 & $(43.4)$ \\
\hline Always & 30 & $(10.1)$ & 4 & (6.9) & 34 & (9.6) \\
\hline \multicolumn{7}{|c|}{ History of genital warts } \\
\hline Yes & 83 & $(27.9)$ & 53 & $(91.4)$ & 136 & $(38.3)$ \\
\hline No & 214 & $(72.1)$ & 5 & (8.6) & 219 & $(61.7)$ \\
\hline \multicolumn{7}{|l|}{ History of STI } \\
\hline Yes & 203 & $(68.4)$ & 56 & $(96.6)$ & 259 & $(73.0)$ \\
\hline No & 94 & (31.6) & 2 & (3.4) & 96 & $(27.0)$ \\
\hline
\end{tabular}

observed in a study conducted by Balandya et al in Dar es Salaam whereby $42.2 \%$ were Aceto white positive [19]. This difference can be explained by the a relatively lower median CD4 count of their population which was 351cells/ $\mathrm{mm}^{3}$ compared to this study where the median CD4 count was 450 cells $/ \mathrm{mm}^{3}$. The lower the CD4 count and advanced
Table 2 Socio-demographic, clinical and reproductive characteristics of HIV+ women screened for CIN

\begin{tabular}{|c|c|c|c|c|c|c|}
\hline \multirow[t]{2}{*}{ Variables } & \multicolumn{2}{|c|}{$\begin{array}{c}\text { CIN } \\
\text { Negative }(n=297)\end{array}$} & \multicolumn{2}{|c|}{$\begin{array}{c}\text { CIN } \\
\text { Positive }(n=58)\end{array}$} & \multicolumn{2}{|c|}{$\begin{array}{c}\text { Total } \\
(n=355)\end{array}$} \\
\hline & $\mathbf{n}$ & $\%$ & $\mathbf{n}$ & $\%$ & n & $\%$ \\
\hline \multicolumn{7}{|l|}{$\begin{array}{l}\text { Exposure to cigarette } \\
\text { smoke }\end{array}$} \\
\hline Yes & 107 & $(36.0)$ & 13 & $(22.4)$ & 120 & (33.8) \\
\hline No & 190 & $(64.0)$ & 45 & (77.6) & 235 & $(66.2)$ \\
\hline \multicolumn{7}{|l|}{$\begin{array}{l}\text { Ever used } \\
\text { contraceptives }\end{array}$} \\
\hline Yes & 108 & $(36.4)$ & 21 & $(36.2)$ & 129 & (36.3) \\
\hline No & 189 & (63.6) & 37 & (63.8) & 226 & (63.7) \\
\hline \multicolumn{7}{|l|}{ Parity } \\
\hline Nullipara & 19 & $(6.4)$ & 5 & (8.6) & 24 & (6.8) \\
\hline $1-2$ & 120 & $(40.4)$ & 15 & $(25.9)$ & 135 & (38.0) \\
\hline $3-5$ & 116 & $(39.1)$ & 33 & $(56.9)$ & 149 & $(42.0)$ \\
\hline $5+$ & 42 & $(14.1)$ & 5 & (8.6) & 47 & $(13.2)$ \\
\hline \multicolumn{7}{|l|}{ Baseline CD4 Count } \\
\hline $\begin{array}{l}\text { Less than } 200 \text { cells/ } \\
\mathrm{mm}^{3}\end{array}$ & 116 & $(39.1)$ & 34 & $(58.6)$ & 150 & $(42.3)$ \\
\hline 200 cells $/ \mathrm{mm}^{3}$ or more & 181 & $(60.9)$ & 24 & $(41.40$ & 205 & $(57.7)$ \\
\hline \multicolumn{7}{|l|}{ Current CD count } \\
\hline $\begin{array}{l}\text { Less than } 200 \text { cells/ } \\
\mathrm{mm}^{3}\end{array}$ & 25 & $(8.4)$ & 7 & $(12.1)$ & 32 & (9.0) \\
\hline 200 cells $/ \mathrm{mm}^{3}$ or more & 272 & (91.6) & 51 & $(87.9)$ & 323 & (91.0) \\
\hline \multicolumn{7}{|l|}{ HIV drugs } \\
\hline Yes & 229 & $(77.1)$ & 49 & $(84.5)$ & 278 & (78.3) \\
\hline No & 68 & $(22.9)$ & 9 & $(15.5)$ & 77 & $(21.7)$ \\
\hline \multicolumn{7}{|l|}{ Years living with HIV } \\
\hline 6 months - 1 year & 57 & $(19.2)$ & 10 & $(17.2)$ & 67 & (18.9) \\
\hline 1 year-2 years & 56 & (18.9) & 10 & $(17.2)$ & 66 & (18.6) \\
\hline 2 years and above & 184 & (61.9) & 28 & $(65.5)$ & 222 & $(62.5)$ \\
\hline
\end{tabular}

stage of HIV could be responsible for a higher prevalence of cervical lesions seen in their study [19]. In the present study, the prevalence of CIN proven by biopsy was $16.0 \%$. Our findings are consistent with a work reported by Miotti et al among 268 postpartum women of Malawi, whereby the prevalence of CIN was 15\% [20]. Although the prevalence of CIN in this population appears to be low, it is within the range described in similar publications in Africa [6,21]. A Botswana study, among HIV infected women using VIA showed a prevalence of $11 \%$, and another study among HIV infected women in Senegal showed a prevalence of $10 \%$ [22,23]. In Africa, a high prevalence of CIN (76\%) among HIV infected women has been observed in Lusaka Zambia [6]. The probable explanation could be a HIV induced immune-suppression as the median CD4 count was low (165 cells $/ \mathrm{mm}^{3}$ ) compared to our study in which the median baseline CD4 count and current CD4 


\begin{tabular}{|c|c|c|c|c|c|c|c|}
\hline \multirow[t]{2}{*}{ Variables } & \multicolumn{2}{|c|}{$\begin{array}{c}\text { CIN } \\
\text { Negative } \\
(\mathbf{n}=297)\end{array}$} & \multicolumn{2}{|c|}{$\begin{array}{c}\text { CIN } \\
\text { Positive } \\
(n=58)\end{array}$} & \multirow[t]{2}{*}{$\begin{array}{l}\text { Crude } \\
\text { OR }\end{array}$} & \multirow[t]{2}{*}{$95 \% \mathrm{Cl}$} & \multirow[t]{2}{*}{ p-value } \\
\hline & $\mathrm{N}$ & $\%$ & $\mathrm{~N}$ & $\%$ & & & \\
\hline \multicolumn{8}{|l|}{ Age } \\
\hline $18-25$ years & 20 & $(6.7)$ & 1 & $(1.7)$ & 1 & & \\
\hline 26-35 years & 95 & (32.0) & 26 & $(44.8)$ & 5.47 & {$[0.70-42.71]$} & 0.105 \\
\hline $36-49$ years & 148 & $(49.8)$ & 24 & (41.4) & 3.24 & {$[0.42-25.30]$} & 0.262 \\
\hline $50+$ years & 34 & (11.5) & 7 & $(12.1)$ & 4.12 & [0.47-35.95] & 0.200 \\
\hline \multicolumn{8}{|l|}{ Marital status } \\
\hline Single & 32 & (10.8) & 5 & (8.6) & 1 & & \\
\hline Married & 107 & $(36.0)$ & 12 & (20.7) & 0.72 & [0.23-2.19] & 0.560 \\
\hline Divorced & 74 & $(24.9)$ & 20 & (34.5) & 1.73 & {$[0.60-5.01]$} & 0.313 \\
\hline Separated & 4 & (1.4) & 2 & (3.5) & 3.20 & [0.46-22.30] & 0.240 \\
\hline Widowed & 80 & (26.9) & 19 & (32.8) & 1.52 & {$[0.52-4.42]$} & 0.442 \\
\hline \multicolumn{8}{|l|}{$\begin{array}{l}\text { Age at } 1^{\text {st }} \text { sexual } \\
\text { intercourse }\end{array}$} \\
\hline $\begin{array}{l}\text { Less than } \\
18 \text { yrs }\end{array}$ & 90 & $(30.3)$ & 44 & (75.9) & 1 & & \\
\hline $\begin{array}{l}18 \text { years and } \\
\text { above }\end{array}$ & 207 & $(69.7)$ & 14 & $(24.1)$ & 0.14 & {$[0.07-0.27]$} & $<0.001$ \\
\hline \multicolumn{8}{|l|}{$\begin{array}{l}\text { No. of live time } \\
\text { sexual partners }\end{array}$} \\
\hline One partner & 16 & (5.4) & 0 & $(0.0)$ & & & \\
\hline 2-5 partners & 235 & $(79.1)$ & 21 & $(36.2)$ & 0.11 & {$[0.06-0.21]$} & $<0.001$ \\
\hline $5+$ partners & 46 & (15.5) & 37 & $(63.8)$ & 1 & & \\
\hline \multicolumn{8}{|l|}{$\begin{array}{l}\text { History of } \\
\text { genital warts }\end{array}$} \\
\hline No & 214 & $(72.1)$ & 5 & (8.6) & 1 & & \\
\hline Yes & 83 & $(27.9)$ & 53 & (91.4) & 27.3 & [10.6-70.8] & $<0.001$ \\
\hline
\end{tabular}

count were 269 cells $/ \mathrm{mm}^{3}$ and 450 cells $/ \mathrm{mm}^{3}$ respectively. Other studies in Tanzania reported a higher CIN prevalence of $32 \%$ and $38 \%[15,17]$. In those studies, conventional cytology was used as a screening method, and biopsy was not done.

The prevalence of CIN in the present study was higher than that found in a study by Mayaud et al among antenatal clinic attendees at the Makongoro clinic Mwanza which was $7 \%$. The difference can be explained by the fact that Mayaud's study involved the general population at the clinic while the present study involved newly diagnosed HIV participants and those who were in follow up for HIV status in tertiary hospital [16]. VIA was offered to 355 women and $26.8 \%$ of these women had VIA positive results. This was similar to a study by De Vuyst et al among 653 women attending Nairobi family planning clinic, whereby $27 \%$ women had VIA positive results [24]. The histological results showed $53.4 \%$ had CIN1 and $46.6 \%$ had CIN2/3, and cervical cancer in $7.4 \%$ women, while in the study done by De Vuyst et al CIN1 was seen in 25\% women, CIN $2 / 3$ in $38 \%$ women and invasive cancer in $4 \%$ women [24]. In our study the frequency of chronic cervicitis with feature of HPV among HIV infected women was $27.4 \%$, this is similar to a study by Mwakigonja et al which showed a cervicitis in $28 \%$, which was dominated by feature of Chlamydia trachomatis [15].

The histological results of CIN and invasive cancer seen in this setting emphasize the importance of introducing a screening programme for cervical cancer in HIV infected women. Despite of being at risk of CIN, none of the participants in this study had previously been screened for cervical cancer. This is a major concern in many developing countries including Tanzania where cervical cancer screening is largely unavailable, leading to late presentation with advance cervical cancer [14].

The majority of women acquired HIV infections within a few years of sexual debut. In this study, an early sexual debut appeared to be associated with the development of CIN but was not statistically significant. This concurs with other studies done in Tanzania whereby an early sexual debut was not directly associated with CIN $[14,17]$. In a study by Matasha et al involving female pupils in Mwanza, 68\% of girls had an early sexual debut [25]. An earlier age of sexual debut implies a longer period of sexual activity and a higher likelihood of having many sexual partners [26]. Having multiple sexual partners exposes a woman to factors predisposing to CIN such as HIV and STI. This was supported by a study done among Nairobi prostitutes that showed that women with multiple sexual partners had an increased risk of developing CIN [27]. A similar trend was seen in the current study, whereby women with many sexual partners (more than two) had more CIN compared to women with few number of sexual partners with significant difference $(\mathrm{P}<0.001)$.

Co-infection with a STI like Chlamydia trachomatis, herpes simplex or genital warts in the presence of HPV increased the risk of CIN by causing inflammation which facilitates HPV persistence and hence cervical lesion and carcinogenesis $[28,29]$. In the present study, a previous history of STI, including genital warts, was associated with CIN. A previous history of STI was reported to be a cofactor needed for the progression of HPV infection to cervical dysplasia and subsequently into cancer. Studies suggest that HIV induced immunosuppression leads to inability to control the HPV expression, hence the persistence of HPV infection and the development of cervical lesions [30]. This study showed that genital warts were associated with an increase risk of CIN. A higher prevalence of HPV infection in Mwanza, found in the study by Mayaud et al could be a major contributor to the increased prevalence of genital warts which was found among HIV infected women in this study. Genital warts are caused by persistent low risk types of HPV 
Table 4 Predictors of CIN on Univariate Logistic Regression

Variables

CIN Negative $(n=297)$

$$
\text { N }
$$

History of STI

No

Yes

\section{4}

203

Exposure to cigarette smoke

$\begin{array}{ll}\text { Yes } & 107 \\ \text { No } & 190\end{array}$

Ever used contraceptives

$$
\text { Yes }
$$

No

Parity

$\begin{array}{lc}0 & 19 \\ 1-2 & 120 \\ 3-5 & 116 \\ 5+ & 42\end{array}$

Years since diagnosed HIV +

$$
\begin{aligned}
& 6 \text { months-1 yr } \\
& \text { 1-2 years } \\
& \text { More than } 2 \text { years }
\end{aligned}
$$

HAART initiated

$\begin{array}{lcc}\text { No } & 68 & \text { (22.9) } \\ \text { Yes } & 229 \\ 4 \text { Count } & & \text { (77.1) }\end{array}$

Baseline CD4 Count

$$
\begin{aligned}
& \text { Less than } 200 \text { cells } / \mathrm{mm}^{3} \\
& 200 \text { cells } / \mathrm{mm}^{3} \text { or more }
\end{aligned}
$$

116

$(6.4)$
$(40.4)$
$(39.1)$
$(14.1)$

$\longrightarrow$

$\frac{\text { CIN Positive }(n=58)}{N}$

Crude OR

$95 \% \mathrm{Cl}$

p-value

$(31.6)$
$(68.4)$

2
56

$$
\begin{aligned}
& (36.0) \\
& (64.0)
\end{aligned}
$$

13
45

(36.4)

(63.6)

21
37

37

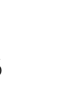

$(3.4)$
$(96.6)$

$(22.4)$
$(77.6)$

(36.2)

(63.8)

5
15
33
5

$(8.6)$
$(25.9)$
$(56.9)$
$(8.6)$

$\begin{array}{ll}(19.2) & 10 \\ (18.9) & 10 \\ (61.9) & 38\end{array}$

1

$\begin{array}{ll} & \\ {[3.1-54.3]} & <0.001 \\ & \\ {[1.01-3.78]} & 0.048\end{array}$

181

Current CD4 count

$$
\text { Less than } 200 \text { cells } / \mathrm{mm}^{3}
$$

200 cells $/ \mathrm{mm}^{3}$ or more

25

$\begin{array}{cc}(8.4) & 7 \\ (91.6) & 51\end{array}$


infection; a history of genital warts in the absence of detectable virus still increases the risk of CIN, as shown by other studies [16,31].

In the current study, women whose baseline CD4 count was less than 200 cells $/ \mathrm{mm}^{3}$ were more likely to have CIN than those patients with a CD4 count of more than $200 \mathrm{cells} / \mathrm{mm}^{3}$. Previous studies have consistently demonstrated that the amount of CD4 count of less than 200 cells $/ \mathrm{mm}^{3}$ is a predictor for having or developing CIN $[14,17]$. A study done by Wright et al in New York in 1994 showed that an age of more than 35 years was associated with a risk of CIN. In the current study, the association between age and CIN was not statistically significant. The same conclusion was reached seen in other studies conducted in Kilimanjaro and Dar es Salaam [14,17].

Although we did not find a significant association between marital status and risk of developing CIN in the present study, a study done in Kilimanjaro showed that single women had a tendency to have multiple sexual partners, a factor which contributed to CIN [17].

Smoking and contraceptive use have been reported to be established cofactors for HPV progression to cervical lesion. Carcinogens produced by tobacco are thought to decrease the immunity in the cervix, thus facilitating HPV persistence [30]. Furthermore, contraceptive hormones increase the expression of HPV genes in the cervix and facilitate HPV persistence [30]. In the present study, the association between CIN and those who have been ever exposed to cigarette and ever used contraception was not significant. Similarly, there was no difference in CIN prevalence between Non ART and ART user. This finding is contrary to a study done by Mwakigonja et al which noted that the frequency of CIN and invasive cancer were higher in women who were non HAART than those who had been on HAART. Initiation of HAART has shown to have an impact on reducing the incidence and progression of CIN [15]. A study by Balandya et al showed that women who had been on ART for more than 1 year had more abnormal cervical changes on VIA compared to those who were on ART for less than a year. The probable explanation is that despite an increased CD4 count with reconstitution of immunity there is no clearance of HPV in the cervix [19]. In the current study, the duration since HIV diagnosis, was not associated with CIN, which is contrary to a study done by Kreiss et al which showed that women living with a HIV infection for more than two years were more likely to carry high risk HPV infections, which could result in CIN, compared to women who had been HIV infected for less than a year [27].

\section{Conclusion}

CIN remains a problem among HIV infected women. A history of multiple sexual partners, a history of genital warts, a history STI and a baseline CD4 T lymphocyte of less than 200cells $/ \mathrm{mm}^{3}$ are significant predictors for CIN. Screening for CIN is recommended for all women with HIV.

\section{Ethical consideration}

Ethical clearance was sought from the Department of Obstetrics and Gynecology and the Joint CUHAS/BMC Research, Ethics, and Publication Committee.

\section{Consent}

An Informed consent was requested from the participants after explaining the aims of the study. For literate women, the consent information was provided followed by a consent form which each participant was required to sign to signify her consent. For illiterate women, the consent information sheet was read in full and participants were requested to place a thumb print on the consent form to signify their acceptance to participate in the study. It was explained that participation was voluntary and those declining to participate were still entitled to the standard care provided to all women at the CTC.

\section{Competing interests}

The authors declare that they have no competing interest. All the authors read through the article and agreed.

\section{Authors' contributions}

LK provided major contributions in concept, study design, literature review, data collection, data entry, data analysis and writing of manuscript. PR contributed to the concept, development of proposal, review of histological slides and writing of manuscript. AM contributed to the development of the proposal and writing of manuscript. NM contributed to the development of the proposal and writing of manuscript. All authors read and approved the final manuscript.

\section{Author information}

First Author, Lilian Kafuruki.

Co Authors, Peter Fabian Rambau (Corresponding author), Anthony Massinde, Nestory Masalu.

\section{Acknowledgements}

We would like to extend our gratitude to Professor Samwel Kalluvya, Dr Alphaxad Kajura, Irene Massawe and Mrs. Shibide Mondea from HIV Care and Treatment Centre for their assistance and cooperation during data collection. Dr Jackson Kahima, Medard Beyanga and Mr. Michael Mulisa for laboratory technical support.

Dr. Rebeca Barila and Dr. Mwita Wambura from National Institute of Medical Research for statistical assistance and Dr Domeneca Morona for her assistance in editing the manuscript

We also thanked senior members of Department of Obstetrics and Gynecology who enriched our proposal and their invaluable input contributed in this study.

\section{Author details}

'Department of Obstetrics and Gynecology, Bugando Medical Centre, Box 1370, Mwanza, Tanzania. ${ }^{2}$ Department of Pathology, Catholic University of Health Sciences and Allied Sciences (CUHAS-Bugando), Box 1464, Mwanza, Tanzania. ${ }^{3}$ Department of Oncology, Bugando Medical Centre, Box 1370, Mwanza, Tanzania.

Received: 13 August 2013 Accepted: 12 October 2013

Published: 15 November 2013 


\section{References}

1. Parkin DM, Freddie B, Ferlay J, Paola P: Global Cancer Statistics, 2002. CA Cancer J Clin 2005, 55:74-10822.

2. Gopal KS, Romuladus EA, Mohammad S: Global Inequalities in Cervical Cancer Incidence and Mortality are Limited to Deprivation, Low Socioeconomic Status, and Human Development. Int J MCH and AIDS 2012, 1(1):17-30,

3. Keita N, Clifford GM, Koulibaly M, et al: HPV infection in women with and without cervical cancer in Conakry, Guinea. Br J Cancer 2009, 101(1):202-220.

4. Lisa MP, Mkuchu J, Ngoma T, et al: Evidence for need of Education Programs for cervical cancer screening in Rural Tanzania. J Cancer Educ 2010, 25(2):153-159.

5. WHO/ICO information Center on HPV and cervical cancer (HPV information center) Human Papillomavirus and related cancer in World Summary Report; 2010.

6. Parham GP, Sahasrabuddhe W, Mwanahamuntu MH, et al: Prevalence and predictors of squamous intraepithelial lesions of the cervix in HIV infected women in Lusaka, Zambia. Gynecol Oncol 2006, 103(3):1017-1022.

7. Franceschi S, Jaffe H: Cervical Cancer screening of women living with HIV infection a must in era of antiretroviral therapy. Clin Infect Dis 2007, 45(4):510-513.

8. Lim FK: Management of Pre malignant lesions of the cervix Ann Academic Med Singapore 2002, 31:557-564.

9. Comprehensive cervical control: a guide to essential practice. Geneva: WHO; 2006.

10. Waggoner SE: Cervical cancer. Lancet 2003, 361(9376):2217-2225.

11. Divya H, Harish S, Prassana KS: Diagnostic value of VIA comparing with conventional papanicolau smear in the detection of colposcopic biopsy proved CIN. Natl J Obstet Gynecol 2011, 6(1):7-12.

12. Ghaemmaghami F, Modarres GM, Marjani M, et al: Assessment of Visual Inspection with Acetic acid (VIA) as a screening test for cervical neoplasia in comparison with cytologic screening. Acta Media Iranica 2003, 41(4):p248-p253.

13. University of Zimbabwe/JHPIEGO Cervical Cancer Project: Visual inspection with acetic for cervical cancer screening; test qualities in a primary care setting. Lancet 1999, 353(9156):869-873.

14. Kapiga SH, Msamanga Gl, Spiegelman D, Mwakyoma H, Fawzi WW: Risk factors for cervical squamous intraepithelial lesions among HIV-1 seropositive women in Dar es salaam. Tanzania Int J Gynecol Obstet 1999, 67(2):87-94.

15. Mwakigonja A, Liset MT, Mwakyoma H, et al: Cervical Cytological Changes in HIV infected patients attending care and treatments clinic at Muhimbili National Hospital, Dar-Es-Salaam Tanzania. Infect Agent Cancer 2012, 7(1):3-8

16. Mayaud P, Gill DK, Weiss HA: The interrelation of HIV, cervical human papillomavirus and neoplasia among antenatal clinic attendee's in Tanzania. Sex Transm Infect 2001, 77(4):248-258.

17. Obure J, Olola O, Masenga G, et al: Prevalence and severity of cervical squamous intraepithelial lesion. Tanzania J Health Res 2009, 11(4):163-169.

18. PEPFAR: Tanzania Operational Plan report FY 2011. FACTS Info, 3.8.3.30:1-442.

19. Balandya BS, Pembe AB, Mwakyoma HA: Cervical premalignant lesion in HIV infected women attending Care and Treatment Centre in Tertiary hospital Dar es Salaam. Tanzania East Africa J Public Health 2011, 8(3):185-189.

20. Miotti PG, Dallabetta GA, Daniel RW: Cervical abnormalities, human papilommavirus, and human immunodeficiency virus infections in women in Malawi. J Infect Dis 1996, 173(3):714-717.

21. Mbakop A, Zekeng L, Mbassi JR: Cytologic aspect of cervical smear in optic microscopy in HIV seropositive women in Younde Cameroon (Central Africa). Arch Anatomy Cytology Pathology 1996, 44(56):250-253.

22. Ramogola-Masire D, de Clerk R, Monare B: Cervical cancer prevention in HIV infected Women using 'See and Treat" Approach in Botswana. J Acquire Immune Defic Syndrome 2012, 59(3):308-313.

23. Hawes SE, Critchlow CW, Sow PS, Toure P, N'Doye I, Diop A, et al: Incidence of high-grade squamous intraepithelial lesions in Senegalese women with and without human immunodeficiency virus type 1 (HIV-1) and HIV-2. J Natl Canc Inst 2006, 98:100-109.

24. De Vuyst H, Claeys P, Njiru S, et al: Comparison of papanicolau smear, Visual Inspection with Acetic acid Human papillomavirus DNA PCR testing and Cervicography International. J Gynecol Obstet 2005, 89:120-126.

25. Matasha E, Ntembela T, Mayaud $P$, et al: Sexual reproductive health among primary and secondary school pupils in Mwanza Tanzania; Need for intervention. AIDS Care 1998, 10:571-582.

26. Dames DN, Cammile R, Andrea G: The prevalence of cervical cytology abnormalities and human papillomavirus in women infected with the Human Immunodeficiency Virus. Infect Agents Cancer 2009, 4(1):S1-S8.
27. Kreiss JK, Kiviat NB, Plummer FA, et al: Human immunodeficiency virus, human papillomavirus and cervical intraepithelial neoplasia in Nairobi prostitute. Sex Transm Dis 1992, 19:54-59.

28. Smith JS, Green J, Peto J, et al: Cervical cancer and use of hormonal contraceptives: a systematic review. Lancet 2003, 361(9364):1159-1167.

29. Smith JS, Bosset L, Munoz N et al: Chlamydia trachomatis and invasive cervical cancer a pooled analysis of the AIRC multicentric case control study. Int J Cancer 2004, 111(3):431-439.

30. Munoz N, Castellsague X, Gonzalez A, et al: Chapter 1, HPV in the etiology of human cancer. Vaccine 2006, 24(3):1-10.

31. Massad S, Katherine R, Kathryn A, et al: Prevalence and Predictors of squamous cell abnormalities in Papanicolau smear from Women Infected With HIV 1. J Acquir Immune Defic Syndr 1999, 21(1):33-41.

doi:10.1186/1750-9378-8-45

Cite this article as: Kafuruki et al:: Prevalence and predictors of Cervical Intraepithelial Neoplasia among HIV infected women at Bugando Medical Centre, Mwanza-Tanzania. Infectious Agents and Cancer 2013 8:45.

\section{Submit your next manuscript to BioMed Central and take full advantage of:}

- Convenient online submission

- Thorough peer review

- No space constraints or color figure charges

- Immediate publication on acceptance

- Inclusion in PubMed, CAS, Scopus and Google Scholar

- Research which is freely available for redistribution
Biomed Central 